\title{
Acções prescritivas e estratégicas: A edição como espaço social
}

Prescriptive and Strategic Actions: Publishing as Social Space

Actions prescriptives et stratégiques: L'édition comme espace social

\section{Nuno Medeiros}

\section{OpenEdition}

\section{Journals}

Edição electrónica

URL: http://journals.openedition.org/rccs/363

DOI: $10.4000 /$ rccs.363

ISSN: $2182-7435$

\section{Editora}

Centro de Estudos Sociais da Universidade de Coimbra

\section{Edição impressa}

Data de publição: 1 Junho 2009

Paginação: 131-146

ISSN: 0254-1106

\section{Refêrencia eletrónica}

Nuno Medeiros, «Acções prescritivas e estratégicas: A edição como espaço social 》, Revista Crítica de Ciências Sociais [Online], 85 | 2009, colocado online no dia 01 dezembro 2012, criado a 02 maio 2019. URL : http://journals.openedition.org/rccs/363 ; DOI : 10.4000/rccs.363 


\section{NUNO MEDEIROS}

\section{Acções prescritivas e estratégicas: A edição como espaço social*}

O propósito deste artigo é o de contribuir para um entendimento da edição como espaço social complexo. Este espaço social é constituído por um conjunto de agentes que actuam como construtores activos na esfera das ideias e da cultura escrita através de uma matriz prescritiva e selectiva da sua intervenção no livro, infundindo-lhe uma identidade própria que extravasa o texto na sua estrita acepção autoral. Por outro lado, o campo editorial e os agentes que o habitam integram processos mais vastos, configuradores de uma indústria específica e governados por interesses relacionados com a constituição de mercados de bens culturais, traduzindo-se este segundo aspecto nos pressupostos estratégicos de ressonância mercantil que suportam a actividade de mediação e prescrição de sentidos.

Palavras-chave: edição; espaço social; prescrição e mediação interpretativas; estratégias editoriais.

A palavra publicada exerce sobre o mundo edificado pelo homem moderno um efeito que simultaneamente o ordena e é atestador desse ordenamento, manifestando-se como um repositório de verdade que, à boa maneira de Michel Foucault (1997), tece um discurso cuja produção carece de permanente organização, distribuição e controlo. No domínio particular do impresso e do tecnicamente disseminável (Furtado, 2000), a edição de livros - aqui definidos como objecto publicado - ocupa um lugar a que a tradição de autonomia autoral nem sempre concedeu relevo na participação essencial nesse processo produtivo. A edição - que aparece como reduto da vida social facilmente assimilado ao livro, traduzindo uma visão longamente reproduzida que tende a colocar o livro numa espécie de lugar específico, central e, para largos grupos, sagrado no contexto do ordenamento do mundo - foi tradicionalmente representada como objecto menor e dis-

* Este artigo beneficiou, numa versão inicial, dos comentários de Diogo Ramada Curto e Jorge Ramos do Ó. Agradeço ainda as observações e sugestões do revisor anónimo ao texto. 
sociado da capacidade de interposição na elaboração desse ordenamento, visto frequentemente como natural.

A superação desta perspectiva remete o esforço analítico para uma concepção da edição como um campo que se desenha por via de uma acção situada num plano primordialmente simbólico de autorização e prescrição das ideias, dos lazeres e da estética, plano esse decomposto inevitavelmente num conjunto de práticas e representações mercantis, sem as quais os processos prescritivos deixam de ser apreensíveis. O livro e, mais latamente, o objecto publicado obedecem, nesta medida, a um jogo subtil e plástico, por vezes turbulento, de ligações, reciprocidades, posições e interesses, aspectos promotores de intervenção estratégica sobre o objecto textual a editar, quer do ponto de vista dos princípios, quer do ponto de vista do mercado de leitores.

\section{Regimes canónicos e prescritivos: a edição como autorização}

Mesmo adoptando a premissa, altamente discutível, de que as ideias podem ser fruto da individualidade, os livros que as disseminam serão indubitavelmente produtos colectivos (Becker, 1984). Se no lado autoral se fazem radicar faculdades de génese das ideias, as entidades que publicam livros acham-se investidas de capacidade mediadora na sua transmissão, ordenando, hierarquizando e constituindo o mercado dos produtos intelectuais (Chartier, 1997). Sujeito de apreciação e de classificação do real, o editor urde a trama tipográfica de autorização de significado. Com pretensões ao controlo do sentido, os textos que publica, configurando um mercado e derivando de escolhas, devem ser lidos e apreendidos sem desvio. Num exercício de nomenclatura inspirado na análise de Zygmunt Bauman (1987) ao papel dos intelectuais, editar é estar dos dois lados da fronteira que separa a modernidade da pós-modernidade nos termos em que o autor o fez. $\mathrm{Na}$ actividade de editar consuma-se, através de uma intervenção no texto que é também co-criação, uma espécie de prática de legislação. O editor participa, assim, na esfera de elaboração das ideias, colaborando nesse empreendimento colectivo que atribui a um conjunto de agentes a propriedade do conhecimento e dos modos de o prescrever. Mas fá-lo igualmente como intérprete, veiculando através da sua interposição saberes e mundividências ao público alargado de leitores e aos próprios agentes especializados, em si mesmo intérpretes face aos seus pares. A actividade editorial inscreve-se, assim, como instrumento institucional de mediação entre autores e públicos, forjando um processo comunicativo entre a elaboração textual e o quadro social mais vasto que o torna possível nos contornos particulares que adquire (Long, 1985), e fazendo parte daquelas "realidades que determinam o sentido" (Viala, 1989: 256). 
A determinação das interpretações leiturais e a interferência nos espaços sociais de circulação de um livro constituem apanágio da presença do editor na obra que edita. Se as opções por um ou outro tipo de diagramação, de letra, pela aposição de subtítulos onde não existiam e supressão dos mesmos onde apareciam, pela adição de ilustrações ou cores, pela introdução de um prefácio ou cronologia, são definidas editorialmente como dispositivos de alívio ou orientação da leitura, a lógica que lhes subjaz é a de mecanismos difractores e refractores de sentido que não esperam públicos compradores, criam-nos. Uma obra com uma extensa alocução técnica de introdução ou abundantes notas explicativas lá colocadas por intermédio do editor, por exemplo, aumenta o seu aparato crítico, apresentando-se ao consumo de franjas diferentes daquelas que a poderiam comprar se expurgada de índices remissivos e impressa em papel "bíblia". Um volume como Os Maias pode sair do prelo como edição escolar ou edição comemorativa. A apresentação tipográfica, a encadernação e o enquadramento editorial de conteúdos de cada uma das propostas serão bem diversos, apontando para uma comercialização diferenciada. A intervenção das materialidades, e crescentemente das imaterialidades, conforma o que é lido e as comunidades que elaboram a leitura (McKenzie, 1986; Furtado, 2006). O preço, resultante das escolhas materiais do editor, instaura uma ordem de hierarquização diferenciadora das representações dos supostos compradores. As edições de luxo, as edições de prestígio, as edições críticas, as edições ilustradas, as edições de bolso, as edições resumidas, inclusive as edições do texto originalmente vertido pelo autor, promovem espaços de movimentação do livro e da ideia de livro que tornam a obra plástica na normatividade adstrita a cada uma das instâncias de recepção na sua variabilidade, tal como vistas do lado editorial (Escarpit, 1958 e 1980; Darnton, 1990).

O perfil de uma editorial, patente no seu catálogo, não obedece apenas aos actos volitivos do editor como instância omnipotente na disseminação e imposição de um conjunto de ideias aos públicos leitores. Também recolhe influência desses mesmos públicos, nos gostos e tendências de leitura sobre os quais o editor procura exercer uma vigilância permanente, baseando os seus passos e o seu dispositivo de selecção e mediação na percepção que produz acerca daquilo a que o mercado - tomado aqui pelo lado da procura - aspira e dos comportamentos de recepção que vai demonstrar. Editar, portanto, consiste não somente no encargo de identificar e isolar subculturas do gosto (Gans, 1974), mas também no incentivo ao aparecimento ou modificação dessas mesmas subculturas. Nestes termos, "a escolha do leitor, sendo livre em abstracto, deriva de encaminhamentos, seduções, constrangimentos" (Medeiros, 2006: 349). 
Donald Lamm (1997) assegura, com alguma ironia, que os únicos obstáculos à vulgarização da auto-edição como norma de publicação, numa época em que os dispositivos tecnológicos viabilizam a possibilidade concreta do oneday publishing ao alcance de todos, são os editores. Com o seu feixe de actos de revisão e edição de texto, de enquadramento plástico e tipográfico do mesmo e de outras "minudências" ignoradas pela maioria dos leitores, os editores conseguem impedir uma passagem só idealmente rápida, directa e linear do texto autoralmente desenhado para o mercado. A interpretação da actividade editorial com base na sua componente de mediação e prescrição dos sentidos conduziu a visões sustentadas na metáfora do editor como árbitro do gosto público (Altbach, 1995), modulando as preferências e os modos de consumir e descortinar os conteúdos das obras que são efectivamente editadas e lançadas para fruição e compra públicas. Também para Michael Lane (1975), a edição ocupa forçosamente um papel na definição activa dos padrões culturais e dos eixos de apreciação. Tecendo uma narrativa do papel cultural do universo editorial, Lane salienta as incidências sociais no campo das ideias de um dos agentes especializados mais relevantes: o editor, isto é, aquele a quem está atribuído o trabalho de articulação com o autor de um texto para a sua transformação a partir de um referencial de colocação no mercado. É possível estender a perspectiva de Lane ao editor (publisher), instância igualmente concebida em larga medida mais como criador e configurador activo da cultura escrita do que como árbitro ou guardião, noções às quais o autor imputa, respectivamente, as ideias de neutralidade e passividade.

"Os editores decidem que tipos de livro serão oferecidos ao público e com quanto vigor serão comercializados. Ao fazê-lo, moldam a criação e a dispersão de ideias, do conhecimento científico e da cultura popular" (Powell, 1985: xv-xvi). Para Irving Louis Horowitz, sociólogo e editor da Transaction Publishers, "uma das mais importantes funções de tornar uma obra pública é exactamente separar o que faz sentido do que não faz" (1986: 162). Nestes termos, "uma editora é definida não apenas pela informação que publica mas também pela que não publica" (ibid.: 35). Os universos prescritivos da edição jogam-se sempre no seu acto inicial, traduzido no dilema: publicar ou não? Actuando como "instrumento de viabilidade do pensamento humano" (Pérez González, 1993: 12), os editores constituem personagens-filtro, decidindo quem merece patrocínio e exclusão na arena de circulação textual, interferindo na própria outorga da distinção autoral. Editar é, então, segundo Pierre Bourdieu, "fazer passar do oficioso ao oficial. A publicação é a ruptura de uma censura" (in Bourdieu e Chartier, 1993:

\footnotetext{
${ }^{1}$ De que foi co-fundador em 1962 com Alvin Gouldner e Lee Rainwater.
} 
294). A recusa ou a aceitação de publicação desempenham, a par de actores como a academia e o Estado, um papel não despiciendo na estruturação da memória impressa e no escalonamento dos textos e autores canónicos de um país, tradição ou grupo social (Petrucci, 1999). Um editor de livros jurídicos, de arte ou de bricolage constrói e defende um panteão para um determinado público, desocultando e autorizando áreas de expressão. A obra-prima só o passará a ser no momento em que, através do processo de publicação, logra escapar ao nada representado pela imagética da "gaveta".

Diferenciando-se notavelmente de uma área de edição para outra, as atribuições de filtragem editorial podem pertencer a outros agentes que não ao editor. Consultores especialistas e agentes literários, entre outros intermediários (de mais escassa presença em mercados do livro pouco diferenciados ou de reduzida dimensão, como o português), concorrem com o editor para a formação de colégios invisíveis de gatekeeping. O crivo editorial é, aliás, um imperativo na ordem dos livros. Se abstractamente não houvesse peneira, tornando exequível a publicação da totalidade da oferta manuscrita, os leitores submergiriam a um dilúvio livresco, submetendo a escolha a uma censura por excesso entrópico (Coser et al., 1982; Neavill, 1975).

Considerar, porém, a actividade editorial, isoladamente nas suas unidades constituintes ou na globalidade do sector, como condição necessária à estruturação e dinamismo da vida intelectual de um dado espaço social, como o nacional, por exemplo, não corresponde a uma relação de proporcionalidade directa entre a actividade editorial e a de produção de pensamento e criação. A dimensão histórica do contexto na sua multiplicidade de variáveis imprime a esta relação as texturas próprias e diferenciadas que ela apresenta nas configurações sociais em que se consuma. Histórias de sucesso como a de Judith Guest, que viu o seu manuscrito não solicitado, Ordinary People, ser resgatado da pilha imensa, confusa, amalgamada, que atafulhava os gabinetes da Viking Press, para uma carreira de vendas ao nível do best-seller, com filme anexo, resistem à generalização. A sua raridade é confirmada se se atender a duas variáveis de contextualização do caso referido: uma, a de constituir a primeira obra publicada em mais de dez anos pela Viking (o ano é o de 1976) a partir de manuscritos da pilha dos não solicitados e, outra, a de a Viking receber nesta época uma média de cinquenta manuscritos por semana - ou 2600 por ano - através desta via (Coser et al., 1982: 106-107). O presidente da Doubleday, uma das maiores editoriais generalistas norte-americanas, afirmava no fim dos anos 1970 que a casa que dirigia recebia cerca de dez mil manuscritos não solicitados por ano. Destes, talvez apenas três ou quatro fossem seleccionados para publicação (Coser et al., 1982: 129-130; Lane, 1980). 
A este propósito, convoca-se para o esforço explicativo o perfil das pequenas editoras, cuja propensão para o público de nicho as torna particularmente permeáveis à edição de propostas em que as designadas editoras estabelecidas recusam pegar - porque operam com valores de escala mais alargados e menos segmentados, logo menos controláveis, mais voláteis e porosos relativamente à plasticidade social de gostos e representações dos compradores de livros. Sendo imprescindível a cautela analítica acerca da assimilação panegírica das pequenas editoras a fonte de maior dinamismo e risco editorial (Medeiros, 2007), certo é que as editoras independentes, sobretudo as que trabalham com tiragens reduzidas, concorrem fortemente para a inovação de estilos e propostas editoriais, publicando a margem, a franja, a subversão, e sobrevivendo apoiadas num conhecimento especializado dos seus públicos e suportadas por redes sociais de fidelização de leitores por via da disseminação informativa e da promoção simbólica de um estatuto de marca que associam à sua reputação. Quando nem mesmo estas se prestam à publicação, resta aos autores o apelo à auto-edição. A edição de autor como recurso não é recente, tendo significado a via privilegiada ou inicial a escritores como Upton Sinclair, Emma Goldman, James Joyce, Walt Whitman ou Mark Twain (McVey, 1975; Henderson, 1995), ilustrando a superação da dependência editorial e cultural da periferia autoral face ao centro. Este tipo de edição permite ainda o que para John Dessauer (1999) pode constituir uma preservação do conteúdo e forma originais da obra publicada, evitando-se a índole formatada das decisões de publicação dominantes em muitas editoras.

Por outro lado, a acção dos editores nesta disponibilização ou indisponibilização de obras e na selecção de autores - circunstância mais frequente do que se pensaria à partida - nem sempre obedecerá a critérios estratégicos ou programáticos. As razões que podem explicar o que é publicado, tornado público, encontram-se num conjunto de deveres e obrigações fundado em sistemas de afectividades, em esquemas de compromissos prévios, em redes de conhecimentos e até em episódios de contactos mais ou menos fortuitos. É na tessitura das relações quotidianas, inclusive no face a face, que reside grande parte da constituição de um fundo bibliográfico e do que se considera como a apresentação de um cânone. Pelo menos para certos contextos, a experiência empírica parece confirmar esta tese. Walter Powell (1985) verificou, para as duas editoras de livros científicos e técnicos que estudou, que as estratégias empregues pelos editores na aquisição de manuscritos para publicação encaixam numa rede social de relações entre editores e autores. Amigos e conhecidos que sugerem ou são sugeridos, de um lado; pares (outros editores ou directores de colecção) e júris cons- 
tituídos formal ou informalmente, a quem se pede uma opinião e a quem se reconhece uma competência particular para apreciar e julgar a qualidade de um texto, de outro, apontam para a importância de que os círculos de sociabilidade se revestem enquanto factor preponderante, quer nos modos de entrega eficaz - no sentido da sua probabilidade de publicação - de manuscritos à leitura editorial, quer nas formas como chegam efectivamente à tipografia como livro a imprimir.

O sortilégio de publicação como elemento de potencial canonização de um escritor nem sempre se verifica na matriz editorial. De facto, o crescente sucesso da prática de publicação de encomendas pode operar em alguns sectores uma modificação do estatuto autoral, conduzindo mesmo em certos casos à sua elisão ou diluição na chancela em que os volumes comissionados são editados. Tramitação habitual no género prático, no de auto-ajuda ou no escolar, o controlo sobre todos os aspectos do livro, da ideia inicial às cores, reside firmemente no editor. Realidade a que Phillip Whitten (1975) dá o nome de managed text, o tempo de consecução é drasticamente reduzido relativamente aos parâmetros normais e a autoria formaliza-se na editora, alterando a relação editor-editado em termos de remuneração e pagamento de direitos.

O reconhecimento desta poliédrica realidade torna, por vezes, difícil falar numa linha filosófica ou política de direcção editorial, reenviando a reflexão para a discussão das intenções e dos efeitos das práticas. Deve haver, pois, algum cuidado ao considerar-se a figura do editor como o elemento central na unificação da globalidade dos processos que fazem de um texto um livro, enquanto participante activo, interessado e consciente na elaboração de uma trama de sentidos possíveis que pretende serem apreendidos pelos potenciais leitores. Mas o editor não deixa de ser um dos motores do processo de construção fiduciária da cultura impressa, isto é, configurou-se como um dos elementos que fabrica - e fabricou - uma das características essenciais do universo tipográfico moderno, justamente pelo que nele se encerra de garantia dada à esfera da crença pelo trabalho editorial de crivo e autenticação: a confiança de que a palavra impressa goza como caução de verdade, destacando-se o livro como paradigma deste regime de autoridade quanto ao conteúdo (Johns, 1998).

\section{Formas de credenciação editorial e estratégias de mercadorização do livro}

O valor social da publicação tende, então, a corresponder, muitas vezes de modo não inteiramente consciente, a uma validação consagradora de verdade ou de capacidade. Este aspecto não deixa de se verificar num contexto de actividade mercantil, cujo eixo é a constituição de um espaço de compra do produto-livro que permita tanto a concretização da eficácia da 
obra publicada - dos pontos de vista da sua recepção e do seu escoamento como a manutenção económica da possibilidade de novas publicações. A disseminação do livro, num contexto de capitalismo tardio, depende efectivamente, na sua existência, da presença de um mercado - e da sua expansão - com forte inclinação para o âmbito do consumo no quotidiano, enviando este consumo nas suas possibilidades de utilização para um modelo industrial de concepção, produção e distribuição. ${ }^{2}$

Sendo verdade que o valor de prescrição não é confundível com o de disseminação do livro, tornado mercadoria transaccionável, ambos os processos são, contudo, indissociáveis. O editor procura, por isso, ter ao seu alcance formas diversas de levar o livro ao leitor, de o seduzir, de lhe despertar a avidez. Prosseguindo deliberadamente um plano alicerçado em intuitos de posicionamento no mercado e no campo, o editor recorre a dispositivos estratégicos para, no limite, tentar estimular junto do eventual leitor a compulsão de aquisição livresca com base numa fobia do sentimento de exclusão da leitura, do conhecimento, de um autor de culto ou de um tema da moda. De eficácia variável, as estratégias editoriais podem chegar a fomentar em consumidores específicos do livro o desenvolvimento de afinidades particulares com determinadas colecções e editoras. Saliente-se, todavia, que a difusão do livro não é necessariamente correlata em proporção da propagação da leitura, embora, extensivamente, constitua um dos indicadores para a sua aferição. A leitura-consulta esporádica e localizada de um dicionário ou enciclopédia, bem como a ostentação das lombadas acetinadas de uma colecção percebida como de referência, são dois exemplos dos riscos da associação directa da compra de livros ao seu uso leitural, conceito, de resto, não linearmente definível e aplicável.

As estratégias e inovações editoriais inscrevem-se, então, no processo de recortar a literatura ou o conhecimento mediante a infusão no texto do factor livro. Não só porque facultam à esfera pública o resultado do labor autoral, erigindo justamente um público e modulando um mercado que deve ser conquistado, mas porque, ao fazerem-no, incorporam no texto um valor de uso e de desejo enquanto objecto - e daí, por exemplo, o constante recurso editorial ao livro álbum, conhecido e reconhecido pelo efeito plástico das cores, materiais e formato ou pelas incidências simbólicas da sua posse. Forjar a necessidade, sublinhando o facto de "determinados tipos

\footnotetext{
2 Teria cabimento neste momento uma exploração das dimensões que enquadram o campo da edição na discussão sobre as indústrias culturais, como, por exemplo, os aspectos técnicos, materiais e de remuneração na reprodução de bens eminentemente simbólicos, ou a tensão imanente entre comércio e cultura na matriz de actividade editorial (Medeiros, 2009a; 2009b). A oportunidade do seu desenvolvimento ocorrerá noutro lugar.
} 
de livros poderem promover determinados tipos de experiências de leitura ao comprador presumido como leitor" (Radway, 1997: 167), ou consolidando a representação do livro como ideia que se consuma na sua posse, é actuar noutra das frentes da construção hermenêutica da edição.

É também neste plano que adquirem expressão analítica as colecções (Olivero, 1999; Cadioli, 2001). Entroncando na produção editorial que induza uma compra continuada, a colecção e a série emparceiram como práticas vetustas com a venda folhetinesca ou por fascículos coleccionáveis. Processo editorial configurador de um padrão a partir da proposição de um modelo que unifica a relação das suas unidades num território reconhecível de coerência, a colecção constitui um dado do maior relevo quanto à forma escolhida pelo editor de produção, comercialização e difusão do livro. Do ponto de vista do pacto que o editor procura firmar com o consumidor final, o "leitor reconhece o livro mas reconhece antes o grupo a que ele pertence" (Borelli, 1999: 461), estabelecendo-se entre livro e série uma dialéctica de benefícios: se um título pode conferir autoridade à colecção em que se insira, também a colecção onde certos livros são publicados pode funcionar como instrumento de credenciação dos mesmos. Legitimidade e potencial mercantil justapõem-se nas modalidades editoriais seguidas, confluindo no sistema comunicativo da palavra impressa. A colecção é, nas palavras de Alain-Marie Bassy, "a mola da edição moderna. Ela organiza o campo da produção. Ela promove a fuga para a frente. Ela cria reflexos de compra" (1991: 616). Desse ponto de vista, a diversificação, patente nos respectivos catálogos, que caracteriza as opções de certas casas editoras pela multiplicação de colecções publicadas, sugere um esquema de compensação interna angariador de margens de suprimento entre os géneros de menor e maior sucesso nas vendas (Carvalho, 1987).

As estratégias a que os editores recorrem no desempenho da sua actividade sofrem a influência interpositiva de outro tipo de preocupações, avultando o proveito simbólico de que podem gozar as editoriais no seio dos membros da comunidade do livro. A credenciação editorial assume, por isso, primazia nas prioridades de actuação prescritiva dos que oficiam na edição. É a editora em si mesma que pode constituir um lastro de reconhecimento com base na reputação obtida ao longo de uma trajectória em que a sua chancela é conotada com um determinado tipo de obra. A reputação, dependente em todos os aspectos das decisões dos seus editores e forçoso instrumento de credibilidade, pode levar longos anos a afirmar-se como bona fides de publicação, entendendo-se a partir do fortalecimento da relação com um público leitor e comprador fidelizado e, sobretudo, com os autores prospectivos, a quem pode servir de dispositivo consagrador. 
Um dos mecanismos de construção e consolidação da reputação editorial consiste no recurso ao legitimismo do perito ou na demonstração de acesso à experiência internacional de casas editoras estrangeiras. No primeiro caso, trata-se de transferir o prestígio, a credibilidade e a celebridade de um autor, coordenador, prefaciador, compilador, tradutor, revisor, ilustrador ou instituição para determinada chancela, plasmando-os especificamente num livro ou latamente num conjunto de livros, esperando que a estratégia funcione como chamariz de vendas, de divulgação, de reverência, ou uma combinação de várias destas variáveis (Powell, 1985). No segundo caso, o apelo a nomes de editoras respeitadas, utilizados na medida em que a sua reputação corresponde a um valor considerado seguro nos esquemas mentais dos leitores, cria nas mundividências de diversos estratos um halo credenciador produzido numa espécie de troca em que a crença na qualidade e na utilidade de uma obra exerce no presumível comprador uma disposição que se poderia designar de fidúcia intelectual. Não é invulgar encontrar apenso aos títulos de certo tipo de edições portuguesas, por exemplo, as designações "Larrouse" nas enciclopédias e "Oxford" nos dicionários.

No domínio concreto da edição literária, poucas variáveis assumiram tanta importância como os prémios, uma das vias de credencialismo e legitimidade com maior tradição. Em universos editoriais nacionais de concorrência historicamente elevada, os prémios consolidaram-se como elemento habitual na vida literária, esperados com regularidade anual ou bienal. As semanas que antecedem a sua entrega geram efervescência entre os actores da edição, magnetizando a atenção dos potenciais compradores e polarizando-a nos favoritos. O fenómeno dos prémios prende-se com uma feição mais comercial do que propriamente literária. Arengar sobre os méritos de um escritor injustamente ignorado ou sobre os deméritos de um autor laureado ergue uma moldura de debate e controvérsia - só esporadicamente de natureza literária - a propósito dos prémios que tem o indubitável efeito de promover o seu poder. E é esse, em larga medida, o poder dos prémios, o de se revelarem vitais para a agitação mediática da vida cultural livresca e para o sucesso financeiro dos editores, mesmo dos que possam não ser agraciados com o galardão (Fouché, 1991). Uma casa que não tenha publicado a obra a quem tenha sido atribuído um Goncourt, um Femina, um Booker ou um Pen Club pode legitimamente aspirar a um crescimento nas vendas se o seu catálogo contemplar outros livros do mesmo autor.

A correspondência entre o zénite simbólico e a potenciação máxima de vendas é, no entanto, possível: cultura e comércio encontram-se harmoni- 
camente no vencedor do Nobel, ${ }^{3}$ talvez o galardão literário que galvanize verdadeiramente as vendas em termos internacionais. Pela virtude exemplificativa vem à colação mencionar a relação de Jérôme Lindon, coluna vertebral e alma da Minuit, com um dos seus autores de eleição, Samuel Beckett. Quando Lindon se dispôs em 1952 a publicar a que se viria a tornar numa das mais representativas peças de dramaturgia do século XX, En Attendant Godot, mais facilmente suporia, tal como o próprio Beckett, que o percurso da obra em termos de vendas se não distanciaria grandemente do que aconteceu no primeiro ano, com a magra cifra de 125 exemplares vendidos, do que o que acabou por acontecer, com o título a vender desde a década de 70, só em França, aproximadamente 30.000 exemplares por ano. Um livro que se poderia vaticinar condenado ao consumo minoritário, transformou-se num verdadeiro livro de fundo, com vendas crescentes, atingindo valores que ultrapassaram o milhão de exemplares vendidos. Emergindo como clássico, superou a lógica dos picos e flutuações, estabilizando-se, por essa via, numa espécie de best-seller de continuidade (Villar, 2002). Evidentemente, a atribuição do prémio Nobel ao autor em 1969 terá reformulado profundamente a equação, consagrando Beckett como um dos dramaturgos maiores do século em que viveu. A aclamação da obra autoral como indicador de notoriedade é, com particular premência no caso em apreço, também fruto do buril do editor e das suas estratégias - lançar a obra para o espaço público, persistir no seu alargamento, inseri-la em determinados círculos de consumo e de produção de opinião, promover a sua internacionalização, entre outras. Interrogado sobre as Éditions de Minuit, Philippe Sollers não enjeita o chiste ao referir-se a este facto: "O Nobel de Samuel Beckett? Qual Nobel? Ah! Quer provavelmente dizer 'o Nobel de Jérôme Lindon"” (apud Simonin, 1994: 393 ).

A atribuição editorial de sentidos ou intenções aos modos de ler a partir da elaboração estratégica de reputação configura-se, por outro lado, na utilização de dispositivos de mediatização de um projecto editorial através do eco obtido pelas obras e autores que uma determinada casa coloca, ou tenciona colocar, nos escaparates. Os blurbs, comentários encomiásticos entre o informativo e o persuasivo publicados nas contracapas ou nas badanas, e as referências explícitas nas cintas ao montante de exemplares vendidos, à cifra de edições ou à atribuição de um dado galardão a um livro, a um autor ou a um tradutor, reflectem maneiras de dar a conhecer o estatuto de uma editora pela qualificação dos autores que publica, exponenciando

\footnotetext{
3 Para uma introdução à geometria do Prémio Nobel da Literatura e uma exploração da "nobelização" como facto social, veja-se João Pedro George (2002: esp. 214-231).
} 
a sua promoção e procurando criar no leitor a proposição auto-representada de uma qualidade editorial intrínseca. Mais heteronomamente, tais mecanismos de propagação estabelecem-se, muitas vezes, na base de uma relação dos editores com os meios de comunicação - através, por exemplo, da pré-publicação de trechos de obras criteriosamente escolhidas - e com um grupo particular de leitores especializados: os críticos. Parecendo dotados da sobrenatural capacidade de fazer a fortuna ou o fracasso de um título, o jornalista cultural ou o crítico especializado no livro, não necessariamente literário, podem definir contextualmente em determinados círculos e comunidades de leitores grande parte das obras que conhecerão debate, valorização, circulação e discussão, ajudando à criação social de uma "consciência do livro" (Altbach, 1995: 272). Evidentemente, a posição que ocupam no espaço social da "formação de juízos culturais" (Ohmann, 1987: 74) estriba-se na autorização da posse de saber pelos pares ou depende do reconhecimento de influência pelo público que lhes consome as orientações ou que é animado por - ou contra - elas.

Por outro lado, não é raro que as redes de relações entre editores e críticos sejam suportadas por interesses comerciais, na medida em que os "editores não são afectados apenas por correntes intelectuais mas também por factores económicos e outros" (Altbach, 1995: 277). Casos, por exemplo, em que uma revista, pertença de uma casa que publique também livros ou fundada por um editor, possua no seu corpo redactorial críticos que sejam igualmente autores editados por essa casa ou por esse editor. ${ }^{4} \mathrm{Ou}$ as concessões que se fazem numa publicação aos grandes anunciantes que, coincidentemente, podem ser - ou necessariamente são - editores, evitando o teor negativo de certas peças ou ampliando a exposição de uma obra ou colecção. A eficácia das críticas aos livros e o seu peso enquanto elemento determinante de leitura e de compra é, evidentemente, uma questão aberta a discussão, sabendo-se que a heterogeneidade dos leitores em termos de interesse, hábito ou gosto no acesso à recensão escrita exerce um forte efeito de dissipação da sua influência. Além disso, sendo apenas sujeita a recensão uma reduzida percentagem dos livros editados, a crítica acaba só por eventualmente afectar o êxito ou o fiasco de um número restrito dos volumes em circulação.

Governada pelas escolhas estratégicas de aumento do mercado e de constituição de novos públicos, a opção dos editores pela credenciação,

\footnotetext{
${ }^{4}$ Um dos exemplos mais conhecidos desta circunstância relaciona-se com o favorecimento da editora norte-americana Random House pela revista de referência The New York Review of Books, iniciada por Barbara e Jason Epstein, então vice-presidente da editora (Ohmann, 1987: 74-75; Epstein, 2001: 115-122).
} 
como por outros dispositivos de reiteração de crença, é reveladora de um corpo ideológico de classe, a que Michel de Certeau (1990) chamou de consumo-receptáculo. Visando a eficácia produtiva, com incidências tanto ao nível das tiragens quanto ao da distinção de frátria, a estratégia editorial pressupõe o efeito - pouco - acessório de uma inércia de consumo. Os editores reproduzem, desta forma, o sistema de enquadramento discursivo de colectivos como o dos escritores, postulando para a sua sobrevivência a permanência de "um público passivo, 'informado', tratado, marcado e sem papel histórico" (Certeau, 1990: 242). Por outro lado, a ampliação de públicos procurada pelo editor pode promover, deliberadamente ou não, uma nova hierarquização social da leitura de um texto e da compra de um livro, asserção que se demonstra com facilidade no contraste possível de estabelecer entre cinco versões d'Os Lusíadas e dos alvos que pretendem atingir: 1) o resumo de tipo sebenteiro, de pequeno formato truncado e anotado; 2) a narrativa em prosa, com ilustrações, linguagem simples e um número de páginas pouco extenso; 3 ) a edição de bolso, com texto integral e glossário explicativo; 4) a edição crítica, apresentada como tal, com texto fixado e longa e densa nota introdutória; e 5) a edição em grande formato, mais uma vez com texto integral, encadernação de luxo e gravuras elaboradas a partir de registos serigráficos de um pintor famoso. Na medida em que o valor do livro editado conhece ampla variabilidade na sua amplitude simbólica e fiduciária em função do seu contexto de utilização, o labor de editores, como de outros agentes do livro, é o da perene expansão dos limites da imaginação criadora de produtos destinados às mais diferentes utilizações leiturais.

\section{Conclusões}

A edição e os seus agentes encontram-se amiúde inscritos em práticas discursivas que facilmente se transportam para os riscos da vulgarização ou da naturalização, associando-se (com especial premência no caso português do universo editorial no século xx) a uma série de opiniões a que acabam por não ser estranhos laivos de folclore e mistificação. Não é invulgar discorrer sobre o sector do livro, ou mesmo explicá-lo, investindo a actividade editorial e os - ou alguns dos - actores que lhe dão corpo de uma matriz heróica, feita de abnegações e benevolências culturais em torno das quais se estabelecem efígies defensoras da pureza das letras e da liberdade de expressão. Inversamente, também não são raros os enfoques que concentram na ideia de autor - e no estabelecimento de uma relação directa entre este e a esfera da recepção - o primado da explicação do que é canónico ou anti-canónico na ordem do livro, elidindo a figura do editor e o quadro 
colaborativo em que se erige a edição. Um dos objectivos que presidiram à sistematização aqui operada consistiu na restituição de um papel fundamental à edição e ao editor na hermenêutica da produção do livro e da cultura escrita em geral, colocando no eixo da análise quer os mecanismos de intervenção prescritiva e mediadora, quer os de mercado industrial da cultura. Subjacente a este propósito firma-se outro, de alcance mais vasto, perceptível na seguinte asserção: uma narrativa que tente compreender a edição e os agentes do livro editado de uma forma que reconheça a sua espessura na sua instabilidade e complexidade deve concebê-los como espaço social feito de oscilações, ambivalências e contradições. A edição surgirá, assim, ao olhar como espaço contingente e plural, aberto e situado historicamente, apreensível como processo sempre permeável à emergência de rupturas e recorrências, irisado por colorações e subtilezas, e onde se constrói a desnaturalização do livro e do ordenamento que por este se faz do mundo moderno.

\section{Referências bibliográficas}

Altbach, Philip (1995), "Publishing and the Intellectual System", in Philip Altbach e Edith Hoshino (orgs.), International Book Publishing: An Encyclopedia. New York/ London: Garland, 271-278.

Bassy, Alain-Marie (1991), "L'édition en marche”, in Roger Chartier e Henri-Jean Martin (dir.), Histoire de l'édition française, 4, Le livre concurrencée: 1900-1950. Paris: Promodis e Fayard, 615-620 [2. ${ }^{a}$ ed.; $\left.{ }^{1} 1986\right]$.

Bauman, Zygmunt (1987), Legislators and Interpreters: On Modernity, Post-Modernity and Intellectuals. Ithaca: Cornell University Press.

Becker, Howard (1984), Art Worlds. Berkeley/Los Angeles/London: University of California Press.

Borelli, Silvia (1999), "Livros, editoras, leitores. Leitura e cultura popular de massa no Brasil”, Revista de história das ideias, 20, 445-470.

Bourdieu, Pierre; Chartier, Roger (1993), "La lecture: une pratique culturelle - débat entre Pierre Bourdieu et Roger Chartier", in Roger Chartier (dir.), Pratiques de la lecture. Paris: Peyot e Rivages, 277-306 [2. ${ }^{a}$ ed. bolso; $\left.{ }^{1} 1985\right]$.

Cadioli, Alberto (2001), Dall'Editoria Moderna all'Editoria Multimediale. Il testo, l'edizione, la lettura dal Settecento a oggi. Milano: Unicopli.

Carvalho, Alberto (1987), "Uma radiografia do mercado editorial", Prelo, 14, 7-12.

Certeau, Michel de (1990), L'invention du quotidien. I, Arts de faire. s.l.: Gallimard [1. ${ }^{\text {a }}$ ed. bolso; $\left.{ }^{1} 1980\right]$.

Chartier, Roger (1997), A ordem dos livros. Trad. de Leonor Graça. Lisboa: Vega [1. ${ }^{a}$ ed. portuguesa; $\left.{ }^{1} 1992\right]$. 
Coser, Lewis et al. (1982), Books: The Culture and Commerce of Publishing. New York: Basic Books.

Darnton, Robert (1990), The Kiss of Lamourette: Reflections in Cultural History. New York: W. W. Norton.

Dessauer, John (1999), Book Publishing: The Basic Introduction. New York: Continuum [4. ${ }^{\mathrm{a}}$ ed.; $\left.{ }^{1} 1974\right]$.

Epstein, Jason (2001), Book Business: Publishing Past, Present and Future. New York, London: W. W. Norton.

Escarpit, Robert (1958), Sociologie de la littérature. Paris: Presses Universitaires de France.

Escarpit, Robert (1980), “Édition”, Encyclopaedia Universalis, 5. Paris: Encyclopaedia Universalis, 956-961.

Foucault, Michel (1997), A ordem do discurso. Aula inaugural no Collège de France, pronunciada em 2 de Dezembro de 1970. Lisboa: Relógio D’Água [1. a ed. portuguesa; ${ }^{1} 1971$ ].

Fouché, Pascal (1991), "L'édition littéraire, 1914-1950", in Roger Chartier e Henri-Jean Martin (dir.), Histoire de l'édition française. 4, Le livre concurrencée: 1900-1950. Paris: Promodis e Fayard, 210-258 [2. ${ }^{a}$ ed.; ${ }^{1} 1986$ ].

Furtado, José Afonso (2000), Os livros e as leituras - novas ecologias da informação. Lisboa: Livros e Leituras.

Furtado, José Afonso (2006), Do papel ao pixel. Do impresso ao digital: continuidades e transformações. Florianópolis: Escritório do Livro.

Gans, Herbert (1974), Popular Culture and High Culture. An Analysis and Evaluation of Taste. New York: Basic Books.

George, João Pedro (2002), O Meio Literário Português (1960-1998). Prémios literários, escritores e acontecimentos. Miraflores: Difel.

Henderson, Bill (1995), "The Small Press Today and Yesterday", in Philip Altbach e Edith Hoshino (orgs.), International Book Publishing: An Encyclopedia. New York, London: Garland, 322-331.

Horowitz, Irving (1986), Communicating Ideas. The Crisis of Publishing in a Post-Industrial Society. New York, Oxford: Oxford University Press.

Johns, Adrian (1998), The Nature of the Book: Print and Knowledge in the Making. Chicago/London: The University of Chicago Press.

Lamm, Donald (1997), “An Independent Publisher Speaks his Mind”, in Gordon Graham e Richard Abel (orgs.), The Book in the United States Today. New Brunswick/London: Transaction, 245-255.

Lane, Michael (1975), "Shapers of Culture: The Editor in Book Publishing", The Annals of the American Academy of Political and Social Science, 421, 34-42.

Lane, Michael (1980), Books and Publishers: Commerce Against Culture in Postwar Britain. Lexington, Mass.: Lexington Books.

Long, Elizabeth (1985), The American Dream and the Popular Novel. Boston: Routledge $\&$ Kegan Paul. 
McKenzie, Donald F. (1986), Bibliography and the Sociology of Texts. London: The British Library.

McVey, Sheila (1975), "Nineteenth Century America: Publishing in a Developing Country", The Annals of the American Academy of Political and Social Science, 421, 67-80.

Medeiros, Nuno (2006), "Editores e Livreiros: que papéis de mediação para o livro?”, in Diogo Ramada Curto (dir.), Estudos de Sociologia da Leitura em Portugal no Século Xx. Lisboa: Fundação Calouste Gulbenkian, 343-385.

Medeiros, Nuno (2007), “As faces plurais da edição”, Le Monde Diplomatique, edição portuguesa, II série (5), 21.

Medeiros, Nuno (2009a), "Cavalheiros, mercadores ou centauros? Traços de actividade e sentido de si dos editores”, in AAVV, Comunidades de leitura. Cinco estudos de sociologia da cultura. Lisboa: Colibri, 23-61.

Medeiros, Nuno (2009b), "Problematizar o objecto consagrado: definindo o livro como ideia e materialidade através da edição", Revista Portuguesa de História do Livro e da Edição, 24, 1-15.

Neavill, Gordon (1975), "Role of the Publisher in the Dissemination of Knowledge", The Annals of the American Academy of Political and Social Science, 421, 23-33.

Ohmann, Richard (1987), Politics of Letters. Hanover: Wesleyan University Press.

Olivero, Isabelle (1999), L'invention de la collection. Paris: IMEC.

Pérez González, Francisco [entrevista a] (1993), "Apostar por Cervantes antes que termine el Quijote”, Nuestros libros - Revista del grupo interamericano de editores, Janeiro, 11-14.

Petrucci, Armando (1999), "Ler por ler: um futuro para a leitura”, in Roger Chartier e Guglielmo Cavallo (orgs.), História da leitura no mundo ocidental, 2. Trad. de Fúlvia Moretto. São Paulo: Ática, 203-227 [1. ${ }^{a}$ ed. brasileira; $\left.{ }^{1} 1995\right]$.

Powell, Walter (1985), Getting into Print: The Decision-Making Process in Scholarly Publishing. Chicago: University of Chicago Press.

Radway, Janice (1997), A Feeling for Books. The Book-of-the-Month Club, Literary Taste, and Middle-Class Desire. Chapel Hill, London: University of North Carolina Press.

Simonin, Anne (1994), Les Éditions de Minuit 1942-1955. Le devoir d'insoumission. Paris: IMEC.

Viala, Alain (1989), "Prismatic effects", in Philippe Desan et al. (orgs.), Literature and Social Practice. Trad. de Paula Wissing. Chicago/London: The University of Chicago Press, 256-266.

Villar, Jorge (2002), Las Edades del Libro. Una crónica de la edición mundial. Madrid: Debate.

Whitten, Phillip (1975), "College Textbook Publishing in the 1970s", The Annals of the American Academy of Political and Social Science, 421, 56-66. 